\title{
Population organization and ranging pattern of Rhesus macaque (Macaca mulatta) at Bandar, Narayanganj
}

\author{
Shamia Farhana Shoma* and Mohammed Mostafa Feeroz \\ Department of Zoology, Jahangirnagar University, Savar, Dhaka-1342, Bangladesh
}

\begin{abstract}
A study was conducted on population organization and ranging pattern of rhesus macaque at Bandar Upazila, Narayanganj, Dhaka from December, 2009 to September, 2010. Direct count method was used to study the group size and composition, and ranging was determined by GPS coordination plotting on the map. A total of 66 monkeys (29 to 37 individuals) were found in two groups with a mean of $33 \pm 5$.6. Among the population $7.6 \%$ adult male, $33.3 \%$ adult female, $9.1 \%$ sub-adult male, $7.6 \%$ sub-adult female, $25.8 \%$ juvenile and $16.7 \%$ was infant. The ratio between adult male and adult female was 1:4.4 and between adult and nonadults was 1:1.4. Day range length varied from $1543 \mathrm{~m}$ to1716m (mean=1638.43 \pm 56.7 ). Home range was completely overlapped and varied negligibly from 45.2 ha. to 45.5 ha. (mean=45.32 \pm 0.2 ). They minimized conflictions by using different time to move. But the growing dependence of these urban macaques on human resources is a matter of concern. Therefore, conservation strategies should be directed to minimize this dependence.
\end{abstract}

Key words: Rhesus macaque, Macaca mulatta, population, group size, ranging pattern.

\section{INTRODUCTION}

There are 10 species of non-human primates found in Bangladesh including one species of slow loris, five species of macaques, three species of langurs and one species of lesser ape. Among the macaques M. mulatta is distributed throughout the country. They are found in all types of natural forests and inside human settlements in rural and urban areas.

Rhesus macaques are well adapted to life near human settlements and sometimes become weed species in recognition of their ability to thrive in densely populated urban areas (Teas et al., 1980; Richard et al., 1989; Southwick et al., 2005). Hasan et al. (2013) mentioned this adaptive characteristic as an evolutionary strategy which made this species the most widely distributed primates in the world. In urban areas of Bangladesh, rhesus macaques are found mostly near Hindu communities (Hasan et al., 2013). Despite having communal as well as ecological values their population is declining due to increased human-monkey conflict for intense resource competition (Feeroz et. al., 1995; Hasan et al., 2013).

Population study of primates and to know their distribution is extremely important as they play a significant role in the ecosystem of those areas. Such studies help to know the present condition of the species and recommend the appropriate conservation measures if

\footnotetext{
* Author to whom all correspondences should be made.
} 
they are in threat. In Bangladesh, details information on the distribution and population composition of primates is very limited (Green, 1978; Gittins, 1980; Khan \& Ahsan, 1981; Feeroz et. al., 1995; Hasan et al., 2013). However, some intensive surveys were conducted on rhesus macaque throughout the country (Feeroz et al., 1995; Feeroz, 2001; Hasan, 2010) as well as some studies also focus on ecology of urban rhesus macaque of the country (Alam, 2008; Afrin, 2008; Kamruzzaman, 2009; Ahmed, 2011). The present study aims to reveal the group size, group compositions of rhesus macaques, to determine their day range and home range at Bandar, Narayanganj.

\section{MATERIALS AND METHODS}

A total 14 days of field surveys were conducted from December, 2009 to September, 2010 spending 120 hours in total (Table 1). At least 8 hours were spent on each day to collect data. Direct count method was used for the population study. Rhesus groups were continuously followed to count all the individuals. GPS coordinates were noted whenever any group of rhesus macaques was found. Group size and composition were recorded for each group. Six age-sex classes were used to characterize macaques viz. adult male, adult female, sub-adult male, sub-adult female, juvenile and infant (Hasan, 2003; 2010). Various visible markings (injury, abnormalities or other characteristic morphology) of group members were also noted for further identification and to avoid repeated counting of one individual. Group size and composition were verified by repeating the survey at a different time of the day and also in different months.

Macaque groups were followed from dawn to dusk to record the day range. The boundaries of home range of each group were determined on the basis of the outermost points visited by the group members as actually observed. Confirm information of the local inhabitants were also under consideration. Core area and peripheral area were determined by the frequent movement of the monkey groups. Finally, the measurement of the day range and home range was done by plotting the GPS coordination in software named 'Arc view GIS 3.3'.

Table 1. Time schedule during study period

\begin{tabular}{lc|c|c}
\hline Month & Days spent & Observation hours \\
\hline December, & 2009 & 1 & 8.00 \\
January, & 2010 & 1 & 8.00 \\
February, & 2010 & 2 & 16.00 \\
March, & 2010 & 1 & 10.00 \\
April, & 2010 & 2 & 18.00 \\
May, & 2010 & 1 & 8.00 \\
June, & 2010 & 3 & 26.00 \\
July, & 2010 & 1 & 10.00 \\
August, & 2010 & 1 & 8.00 \\
September, 2010 & 1 & 8.00 \\
\hline Total & 14 & 120.00 \\
\hline
\end{tabular}


Study area: The study was conducted in Bandar Upazila $\left(23^{\circ} 36.903^{\prime} \mathrm{N}\right.$ and $90^{\circ} 30.716^{\prime}$ E) of Narayanganj District. It is bound by Shitalakshya river on the west and one of her branches runs on the south boundaries of this area. It is a very busy area close to human settlements comprising a bazar and suitable range of vegetation. The bazar and adjacent human habitation were highly exploited by the macaque groups. They largely subsist on natural vegetation, agricultural vegetables, home garden and prepared food items removed from houses and shops in the bazar area as well. Bread, biscuits, crackers and other items were also given to the monkeys by local people and visitors. Most common vegetation of this area included mango (Mangifera indica), black berry (Syzygium cumini), papaya (Carica papaya), jackfruit (Artocarpus heterophyllus), litchi (Litchi chinensis), guava (Psidium guajava), wood apple (Aegle marmelos), hog plum (Spondias mombin), coconut (Cocos nucifera), betelnut palm (Areca catechu), banana (Musa paradisiaca), mehgoni (Swietiana fomes), rain tree (Samanea saman) etc. Bean (Lablab purpureus), tomato (Lycopersicon esculentum), drumstick (Moringa oleifera), brinjal (Solanum melongena) etc. were found as agricultural vegetables.

\section{RESULTS AND DISCUSSION}

Two groups with a total of 66 monkeys were found. The mean group size was $33 \pm 5.6$ individual (ranging from 29 to 37 individuals). The population comprised of 5 adult males (7.6\%), 22 adult females (33.3\%), 6 sub-adult males (9.1\%), 5 sub-adult females (7.6\%), 17 juveniles (25.8\%) and 11 infants (16.7\%) (Fig. 1).

Between two groups of macaques, Group-1 was larger than Group-2 and contained 37 individuals. It comprised of $8.1 \%$ adult male, $32.4 \%$ adult female, $10.8 \%$ sub-adult male, $8.1 \%$ sub-adult female, $24.3 \%$ juvenile and $16.2 \%$ infant. It was divided into three sub groups, each sub-group possessed 8, 11, and 18 individuals, respectively (Table 2).

Group-2 possessed 29 individuals dividing into two sub-groups where each sub-group contained 14 to 15 individuals. Among the population of Group-2, 6.9\% adult male, $34.5 \%$ adult female, $6.9 \%$ sub-adult male, $6.9 \%$ sub-adult female, $27.6 \%$ juvenile and $17.2 \%$ infant (Table 2).

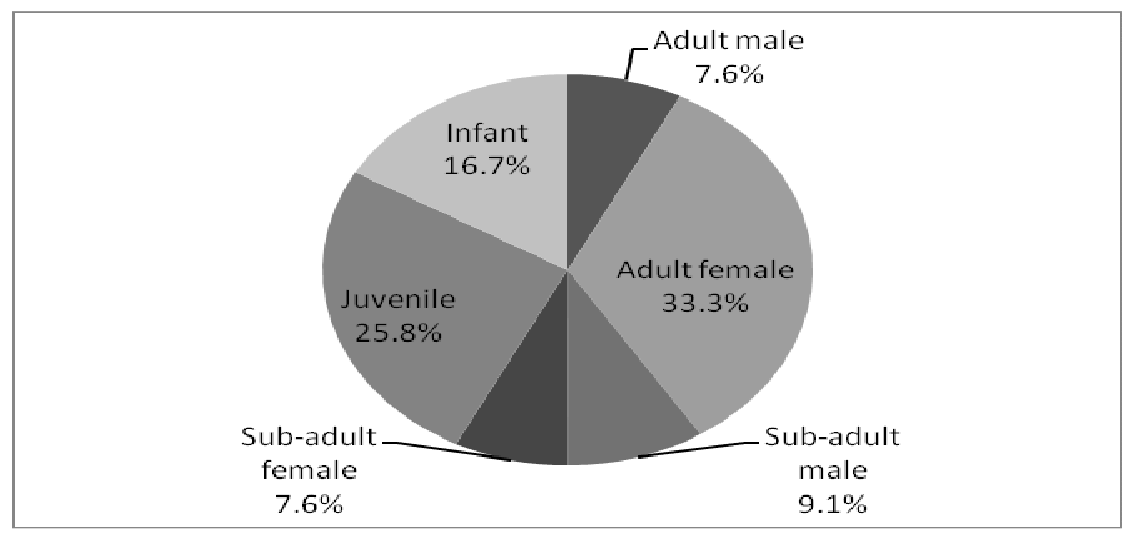

Fig. 1. Composition of rhesus population at Bandar 
The number of adult males in the groups varied from 2 to 3 and of adult females from 10 to 12 . The adult sex ratio was 1:4.4 (1 male to 4.4 females) while the ratio between adult and non-adults (immatures) was 1:1.4. The ratio between adult female and infant was 1:0.5 which depicts a good reproductivity in females.

Table 2. Group size and composition of two groups of rhesus population at Bandar

\begin{tabular}{l|c|c|c|c|c|c|c|c|c}
\hline Group & \multicolumn{5}{c|}{ Group-1 } & \multicolumn{4}{c}{ Group-2 } \\
\cline { 2 - 10 } & $\begin{array}{c}\text { Sub- } \\
\text { group } \\
1\end{array}$ & $\begin{array}{c}\text { Sub- } \\
\text { group } \\
2\end{array}$ & $\begin{array}{c}\text { Sub- } \\
\text { group } \\
3\end{array}$ & Total & $\%$ & $\begin{array}{c}\text { Sub- } \\
\text { group } \\
1\end{array}$ & $\begin{array}{c}\text { Sub- } \\
\text { group } \\
2\end{array}$ & Total & $\%$ \\
\hline Adult male & 1 & 1 & 1 & 3 & 8.1 & 1 & 1 & 2 & 6.9 \\
Adult female & 3 & 3 & 6 & 12 & 32.4 & 5 & 5 & 10 & 34.5 \\
Sub-adult male & - & 2 & 2 & 4 & 10.8 & 1 & 1 & 2 & 6.9 \\
$\begin{array}{l}\text { Sub-adult } \\
\text { female }\end{array}$ & - & 1 & 2 & 3 & 8.1 & 2 & - & 2 & 6.9 \\
Juvenile & 3 & 2 & 4 & 9 & 24.3 & 3 & 5 & 8 & 27.6 \\
Infant & 1 & 2 & 3 & 6 & 16.2 & 2 & 3 & 5 & 17.2 \\
\hline Group size & \multicolumn{7}{c}{37}
\end{tabular}

A wide range of area was covered by rhesus macaques for their different activities. Day range length varied from $1543 \mathrm{~m}$ to $1716 \mathrm{~m}$ (mean= $1638.43 \pm 56.7, \mathrm{n}=14)$. The home range was completely overlapped (Fig. 2) and measured as 45.5 ha. and 45.2 ha. for Group-1 and Group-2, respectively with a mean of $45.32 \pm 0.2$ ha. Within this home range rhesus macaques moved to collect food materials and fulfilled their other fundamental needs.

The frequently used sites of macaques were Kazi Villa, Police phari, Fire Service Office, Bandar Girl's School, Bandar Shishu Niketon, Bazar area, Amin Residential Area, Babupara, Jamaipara, Salehnagar, Baroipara and Razbari. These areas were used as major feeding and resting grounds of macaques due to easy access to their resources.

Both the groups used same area and overlapping routes (Fig. 3) occupying different times which minimized conflictions between them. The position of Police phari, Bazar area, Kazi villa and Babupara were vital in their route and these areas were highly overlapped by the two groups where collisions mainly occurred. They spent late noon at the Bazar and nearby areas. Another common route comprised of Fire Service office, Bandar shishu Niketon (school) and its adjacent human habitations. During the study period, at 11AM12PM Group-1 mainly found in Razbari area whereas Amin Residential Area was frequently used by Group-2 at that time. 


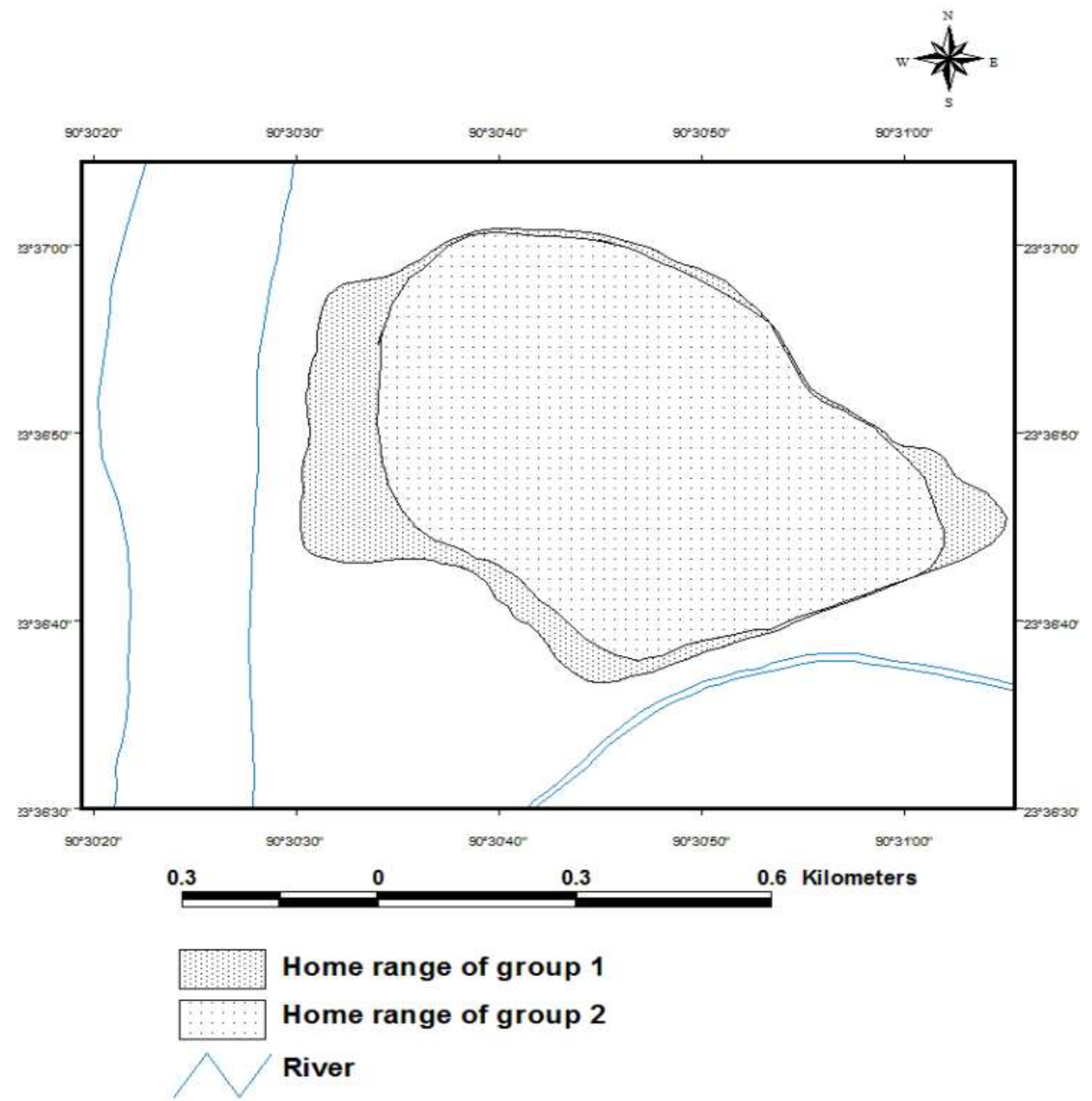

Fig. 2. Home ranges of rhesus macaques at Bandar

Bangladesh is a small developing country with a large number of populations. Due to raising human population pressures and rapid urbanization, habitats of rhesus macaques are becoming fragmented (Hasan, 2003; 2010). Bandar is a crowded area accompanied with multistoried buildings and because of these reasons its vegetation is decreasing day by day. But surprisingly a moderate number of rhesus macaques (66) was found to live here as commensal with human. This might be due to their high adaptive power. According to Dunbar (1988), population density is greatly affected by the quality of habitat. Alam (2008) reported the presence of two macaque groups of 35 individuals (range: 14-21 individual) at Bandar as a part of his M.Sc. thesis while Kamruzzaman (2009) had found 48 individuals in two groups. Hasan et al. (2013) mentioned that there were two groups with a total population of 55 macaques, varied from 25 to 30 individuals. The number of rhesus population varied with surveys. The scenario of these 
previous surveys along with the present study shows the increasing trend of rhesus macaques at Bandar. The improved nutritional value of a provisioned diet is known to enhance fecundity, resulting in population growth (Mori, 1979; Lyles \& Dobson, 1988). Hasan (2010) also claimed the provisioning as a factor for high population growth rate in urban macaques. Easy access to provisioning food besides of natural food may be one of the probable factors for the increasing population growth rate at Bandar. As these monkeys were partly dependent on human food source, they were found to steal human food and to forage at Bazar area frequently. Sometimes they were found to take food from human waste food stuff.
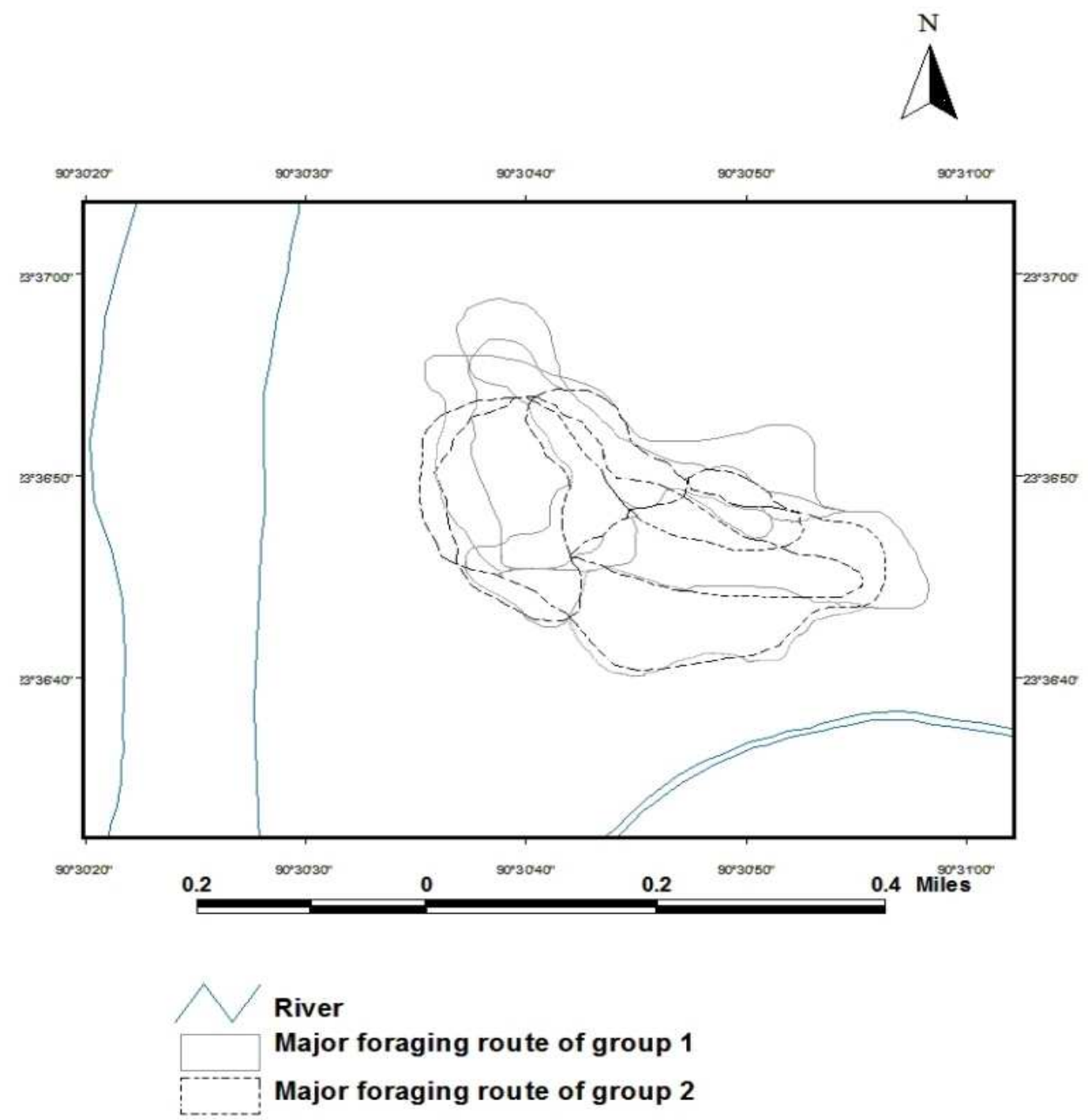

Fig. 3. Major foraging routes of rhesus macaques at Bandar 
Each group contained higher number of females than that of males. This is the result of female philopatry and male dispersal characteristics of macaques. Generally females remain in their natal groups whereas males may leave their natal group when they become mature. Here, groups were composed primarily of females and juveniles, followed by infants, sub adults and adult males.

Ranging pattern of macaques depends on various inter-related factors of the groups, such as body size, food abundance, weather and energy cost (Chivers, 1975; Raemaekers, 1977). Dunbar (1988) stated that habitat quality is probably the most important factor influencing range size. At Bandar, day range of macaques was greatly affected by the human interference. The day range recorded by Kamruzzaman (2009) was about 2000m to $3000 \mathrm{~m}$ which is higher than that of the present study $(1543 \mathrm{~m}$ to $1716 \mathrm{~m})$. This is because of the growing dependence on some particular areas from which they can exploit their resources easily. Home range was extensively overlapped where home range of Group-2 was laid entirely within the home range of Group-1. Home range size is primarily determined by the availability of resources (Teas et al., 1980) and is also related to the size of a group or the weight of a group (Chivers, 1974; Oaters, 1987). Larger groups tend to occupy the largest home ranges, as more resources are required to sustain a greater number of individuals (Teas et al., 1980). Here, home range of two groups differed negligibly in size (45.2 ha. to $45.5 \mathrm{ha}$.). This might be due to their close group size. No adequate data on ranging pattern of macaques at Bandar is available to compare with the present study. Local information suggested that macaques used a larger area in the past but now they are found only at Bazar areas and nearby localities. Decreasing natural food sources due to gradual declination of vegetation and their high dependence on human foods are the probable reasons of confined home range.

Presence of trees and availability of other food products were important factors to select foraging sites of macaque groups. Some important foraging sites were Bazar areas, Bandar shishu Niketon, Police phari, Baroi para etc. During summer, Police phari was mostly used as there was a big mango tree and macaques were seen to consume a large number of green mangoes. A big rain tree at the school was also used in search of their food. Roosting sites at Bandar consisted of trees, walls and roof of building. Most commonly used resting sites were Kazi Villa, Razbari, Police phari, Bandar Shishu Niketon, Fire Service Office, Bandar Girl's School \& College and some buildings of Amin Residential Area.

In urban areas, human interference is an important factor for living pattern of macaques (Roy, 2010). Human-monkey confliction is a growing problem for both human and monkey species. Many people claimed these monkeys as nuisance because they damage human resources in search for foods (Roy, 2010). Even some people are scratched and bitten by the monkeys. On the other hand, monkeys are also injured and killed by the local people. Increased group size and a growing reliance on humans at Bandar may bring it's macaques into increased conflict with residents in the future which can be a high risk for their population. Moreover, these interactions may increase the risk of bidirectional disease transmission (Jones-Engel et al., 2008). Notwithstanding the negative aspects, 
monkeys are perceived to be an important part of the environment and also have traditional and cultural values. So, human-monkey relationship should be manageable for the well-being of both species through appropriate management practices.

\section{REFERENCES}

Afrin, S. 2008. Ecology and behavior of Rhesus macaque (M. mulatta) at Dhamrai. M. Sc. Thesis, Department of Zoology, Jahangirnagar University, Savar, Dhaka, Bangladesh.

Ahmed, S. 2011. Ecology and behavior of Rhesus macaque (M. mulatta) at Chashnimirer Mazar and Malanichara Tea Garden, Sylhet. M. Sc. Thesis, Department of Zoology, Jahangirnagar University, Savar, Dhaka, Bangladesh.

Alam, R. 2008. Status, distribution and ecology of Rhesus macaque (M. mulatta) in urban areas of Bangladesh. M. Sc. Thesis, Department of Zoology, Jahangirnagar University. Savar, Dhaka, Bangladesh.

Chivers, D. J. 1974. Daily patterns of Ranging and Feeding in Siamang. Proc. $5^{\text {th }}$ Int. Congr. Primat. Nagoya. 1974. In: S. Konds, M. Kawai and A. Ehara, (eds.). Contemporary Primatology. pp. 362-372. Karger, Basel.

Dunbar, R. I. M. 1988. Primate social system. Croom Helm. pp. 1-137.

Feeroz, M. M. 2001. Species diversity and population density of non-human primates in north-east and south-east of Bangladesh. Ecoprint 8(1): 53-57.

Feeroz, M. M., Islam, M. A. and Kabir, M. M. 1995. Status, distribution and conservation of nonhuman primates of Bangladesh. Kyoto Univ. Overseas Research Report of Studies on Asian Non-human Primates 9: 73-82.

Gittins, S. P. 1980. A Survey of the Primates of Bangladesh. Project Report to the Forest Department of Bangladesh.

Green, K. M. 1978. Primates of Bangladesh: a preliminary survey of population and habitat. Biol. Conserv. 13: 11-160.

Hasan, M. K. 2003. Hoolock gibbon of Bangladesh: Status distribution and ecology. M. Sc. thesis, Department of Zoology, Jahangirnagar University, Savar, Dhaka, Bangladesh.

Hasan, M. K. 2010. Population Organization and Genetic Variation of Rhesus Macaque (Macaca mulatta) Living in Urban Areas of Bangladesh. MPhil thesis, Department of Zoology, Jahangirnagar University, Savar, Dhaka, Bangladesh.

Hasan, M. K., Aziz, M. A., Alam, S. M. R., Kawamoto, Y., Jones- Engel, L., Kyes, R. C., Akhtar, S., Begum, S. and Feeroz, M. M. 2013. Distribution of Rhesus Macaques (Macaca mulatta) in Bangladesh: Inter-population Variation in Group Size and Composition. Primate Conservation 26: 125-132.

Jones-Engel, L., May, C. C., Engel, G. A., Steinkraus, K. A., Schillaci, M. A., Fuentes, A., Rompis, A., Chalise, M. K., Nantiya, A., Feeroz, M. M., Grant, R., Allan, J. S., Putra, A., Wandia, I. N., Watanabe, R., Kuller, L., Thongsawat, S., Chaiwarith, R., Kyes, R. C. and Maxine, L. L. 2008. Diversity contexts of zoonotic transmission of Simian Foamy Viruses in Asia. Emerg. Infect. Dis. 14(8): 1200-1208.

Kamruzzaman, M. 2009. Social Organization and Actvity Pattern of Rhesus Macaque (Macaca mulatta) at Narayanganj, Dhaka. $4^{\text {th }}$ year B. Sc. Honours report, Department of Zoology, Jahangirnagar University, Savar, Dhaka, Bangladesh.

Khan, M. A. R. and Ahsan, A.W. 1981. The population status of the non-human primates of Bangladesh. Reports of University Grants Commission, Dhaka.

Lyles, A. M. and Dobson, A. P. 1988. Dynamics of provisioned and unprovisioned primate populations. In: Fa, J. E., Southwick C.H. (eds.). Ecology and behavior of food-enhanced primate groups. pp. 167-198. Alan R. Liss Inc., New York. 
Mori, A. 1979. Analysis of population changes by measurement of body weight in the Koshima troop of Japanese macaques. Primates 20:371-397

Oaters, J. F. 1987. Food distribution and Foraging behavior. In: Smuts, B. B., Cheney, D. L., Seyfarth, R. M., Wrangham, R. W. and Strushsaker, T. T. (eds.). Primate Societies. pp. 197-209. The University of Chicago Press, Chicago.

Raemaekers, J. J. 1977. Gibbons and trees: comparative ecology of the siamang and lar gibbons. $\mathrm{Ph}$. D. Thesis. University of Cambridge, Cambridge.

Richard, A. F., Godstein, S. J. and Dewar, R. E. 1989. Weed macaques: The evolutionary implications of macaque feeding ecology. Int. J. Primatol. 6: 569-594.

Roy, S. S., Human-monkey conflict in Bandar Upazilla, Naratanganj. 2010. $4^{\text {th }}$ year B. Sc. Honours report, Department of Zoology, Jahangirnagar University, Savar, Dhaka, Bangladesh.

Southwick, C. H., Malik, I. and Siddiqi, M. F. 2005. Rhesus commensalism in India: problems and prospects. In: J. D. Peterson and J. Wallis (eds.). Commensalism and Conflict: The Human Primate Interface. pp. 241-257. American Society of Primatologists publications, Norman, Oklahoma.

Teas, J., Richie, T., Taylor, H. and Southwick, C. 1980. Population patterns and behavioral ecology of rhesus monkeys (Macaca mulatta) in Nepal. In: Lindburg, D.G. (eds.). The Macaques: Studies in Ecology, Behavior, and Evolution. pp. 247-262. Van Nostrand Reinhold, San Francisco. 